\title{
A Study of Multiple Intelligences of Students in Context to Gender
}

\author{
Dr. Jignasa Joshi ${ }^{1 *}$
}

\section{ABSTRACT}

Education has expanded rapidly in the present times. New institutions are developed because of the Globalization of education every day. The education field hasn't improved as much qualitatively as it has expanded quantitatively. The number of educated unemployed is rising day by day. The person is not getting any skill for life preservation after studying in an educational institution for long time. The current system of education is not complementing the individual differences. No two creatures on this earth are alike. This should be kept in mind while making policy in education. Is there any significant difference of Gender on Multiple Intelligence? To find answer of this question present study was conducted by keeping in mind different intelligence predispositions given in the theory of Multiple Intelligences.

Keywords: Multiple Intelligence, Howard gardener, Higher Secondary School

\section{Preface}

Vast number of research is conducted to the individual difference in the intelligence of the students. This gave birth to too many theories related to intelligence. The uni-factor theory, twofactor theory, multifactor theory is the major ones. Most of the theories are based on the logical and verbal intelligence of the students. This had delimited the field of measurement of the intelligence. There are many people in society who have developed not because of logical power or verbal intelligence but because of other abilities. Thus, the "theory of Multiple Intelligences" of Howard Gardener is worth considering.

\section{Statement of the problem}

The present study was conducted on the higher secondary school $11^{\text {th }}$ standard students know the Multiple Intelligences in reference to gender. The research problem was worded as follows:

\section{A STUDY OF MULTIPLE INTELLIGENCES OF STUDENTS IN CONTEXT TO GENDER}

\footnotetext{
${ }^{1}$ H.O.D., S.S. Patel College of Education, Kadi SarvaVishwavidyalaya, Sector-23, Gandhinagar-382023 (Gujarat), India

*Responding Author

(C) 2016 I J Joshi; licensee IJIP. This is an Open Access Research distributed under the terms of the Creative Commons Attribution License (http://creativecommons.org/licenses/by/2.0), which permits unrestricted use, distribution, and reproduction in any Medium, provided the original work is properly cited.
} 


\section{A Study of Multiple Intelligences of Students in Context to Gender}

\section{Objectives of the study}

Objectives for presented study were as followed:

1. To study the Multiple Intelligences predispositions of the $11^{\text {th }}$ standard students.

2. To study the effect of gender on the Multiple Intelligences predispositions of the $11^{\text {th }}$ standard students.

\section{Hypothesis of the study}

Following null hypotheses was formulated for objectives of the study:

HO $_{1}$ There will not be significant difference in the mean scores on the Multiple Intelligences of the male and female students.

1.1 There will not be significant difference in the mean scores on the Logical intelligence of the male and female students.

1.2 There will not be significant difference in the mean scores on the Linguistic intelligence of the male and female students.

1.3 There will not be significant difference in the mean scores on the Musical intelligence of the male and female students.

1.4 There will not be significant difference in the mean scores on the spatial intelligence of the male and female students.

1.5 There will not be significant difference in the mean scores on the Bodily-Kinaesthetic intelligence of the male and female students.

1.6 There will not be significant difference in the mean scores on the Interpersonal intelligence of the male and female students.

1.7 There will not be significant difference in the mean scores on the Intrapersonal intelligence of the male and female students.

1.8 There will not be significant difference in the mean scores on the Naturalist intelligence of the male and female students.

Variables included in the study

Dependent and independent variables of present study are as follows.

Table 1: Classification of Variables According to Types and Level

\begin{tabular}{|c|c|c|}
\hline Type of variable & Variable & Level \\
\hline \multirow{2}{*}{ Independent variable } & \multirow{2}{*}{ Gender } & Male \\
\hline & & Female \\
\hline \multirow{8}{*}{ Dependent variable } & \multirow{8}{*}{ Multiple Intelligence } & Logical Intelligence \\
\hline & & Linguistic Intelligence \\
\hline & & Musical Intelligence \\
\hline & & Spatial Intelligence \\
\hline & & Bodily-Kinaesthetic Intelligence \\
\hline & & Interpersonal Intelligence \\
\hline & & Intrapersonal Intelligence \\
\hline & & Naturalist Intelligence \\
\hline
\end{tabular}




\section{A Study of Multiple Intelligences of Students in Context to Gender}

\section{Importance of the study}

The knowledge created through this research will be useful to following different concerning parties.

The findings of the study will help in understanding the individual differences in the students.

The knowledge about the Multiple Intelligences of the higher secondary students will facilitate the curriculum developers in including and emphasizing different Intelligence.

The knowledge of Multiple Intelligences will help in guidance and counselling.

The tool constructed in the present study will be useful to know the Multiple Intelligences of the higher secondary students.

The present study will give directions to future research as this research field has not been much done with.

\section{Limitations and Delimitations of the study}

Despite maximum efforts in the research, following are the limitations and delimitations of the study because certain constraints.

The study was delimited to the Gujarati medium higher secondary $11^{\text {th }}$ standard students of Gandhinagar district only.

A self-constructed tool was used for data collection; therefore the limitations of the tool are limitations of the research.

The present study included gender as variables.

\section{Population and Sampling}

The population of the study consisted of the Gujarati Medium Higher secondary school male and female students of Gandhinagar district studying in $11^{\text {th }}$ standard. Total 387 students were selected by using stratified random cluster sampling technique out of which 205 male and 182 female students.

\section{Research method}

Different research method evolved to solve different research problems are called research method. These methods are divided into three type's i.e. historical research method, descriptive research method and experimental research method. The descriptive research method was used as there was description of data collection and analysis. The sub research method was the survey research method.

\section{Tool construction}

The researcher constructed a Multiple Intelligences Inventory to get the data of Multiple Intelligences of the $11^{\text {th }}$ standard students. The Inventory was constructed according the following steps. 


\section{A Study of Multiple Intelligences of Students in Context to Gender}

\section{1 primary form}

The researcher constructed a primary form of Multiple Intelligences Inventory using the collected sentences. 90 sentences were selected and arranged randomly in the Multiple Intelligence Inventory. There were five points against each item to be responded i.e. completely agree, Agree, Neutral, Disagree and completely disagree. The marking for the five points was respectively 5, 4, 3, 2, and 1 for completely agree, Agree, Neutral, Disagree and completely disagree.

\section{Second form}

The second form of the Multiple Intelligences Inventory is prepared based on the suggestions of the experts. There were total 88 items out of which 11 items were related to each predisposition of Multiple Intelligences each.

\section{Piloting}

Piloting was done for the standardization of the second form of the Multiple Intelligences Inventory. 90 representative students were selected for the pilot-study.

\section{Item analysis}

The items having t-value showing no significant difference were removed. Then the items with high correlation were retained in the final form of the Multiple Intelligence Inventory.

\section{Final form of the Multiple Intelligence Inventory}

Total 6 Items for each component were selected for the final form of the Multiple Intelligence Inventory based on the time taken for response and the expert opinions and the statistical significance and correlations were also kept in mind. Thus there were total 48 items in the final Multiple Intelligence Inventory. The students responded according to their degree of relevance and they got 1 to 5 score.

\section{Data collection}

The researcher took the permission of the principals of the respective schools for the data collection from the selected higher secondary school $11^{\text {th }}$ standard students of Gandhinagar district. The researcher went to the schools according to the given date and time and acquainted the principals with the objectives of the research and the tool and thus cooperation was asked. Thus, necessary data collection was done by giving proper instruction to the students and thus taking it in the time convenient to all.

\section{Data analysis}

The score on each component of the Multiple Intelligence Inventory was calculated for each student for further statistical analysis. Then they were classified according to difference variables. The mean score of the whole group was calculated for each component. The significance in the difference of mean scores was tested using Critical Ratio. Thus, mean, 


\section{A Study of Multiple Intelligences of Students in Context to Gender}

standard deviation, Critical Ratio were used for the data analysis. The M.S. EXCEL computer programme was used for the data analysis.

\section{Objective wise Interpretation of data}

Objective-1: To study the Multiple Intelligences predispositions of the $11^{\text {th }}$ standard students.

The highest mean score among the eight Multiple Intelligences was in the Logical Intelligence with 20.73. Then other Intelligence had mean scores in descending order respectively 20.71 for Interpersonal intelligence, 20.60 for naturalistic Intelligence, 19.11 for Bodily intelligence, 19.07 for Spatial intelligence, 18.73 for Linguistic intelligence, 17.76 for the Intrapersonal intelligence and the lowest 16.54 for the Musical Intelligence.

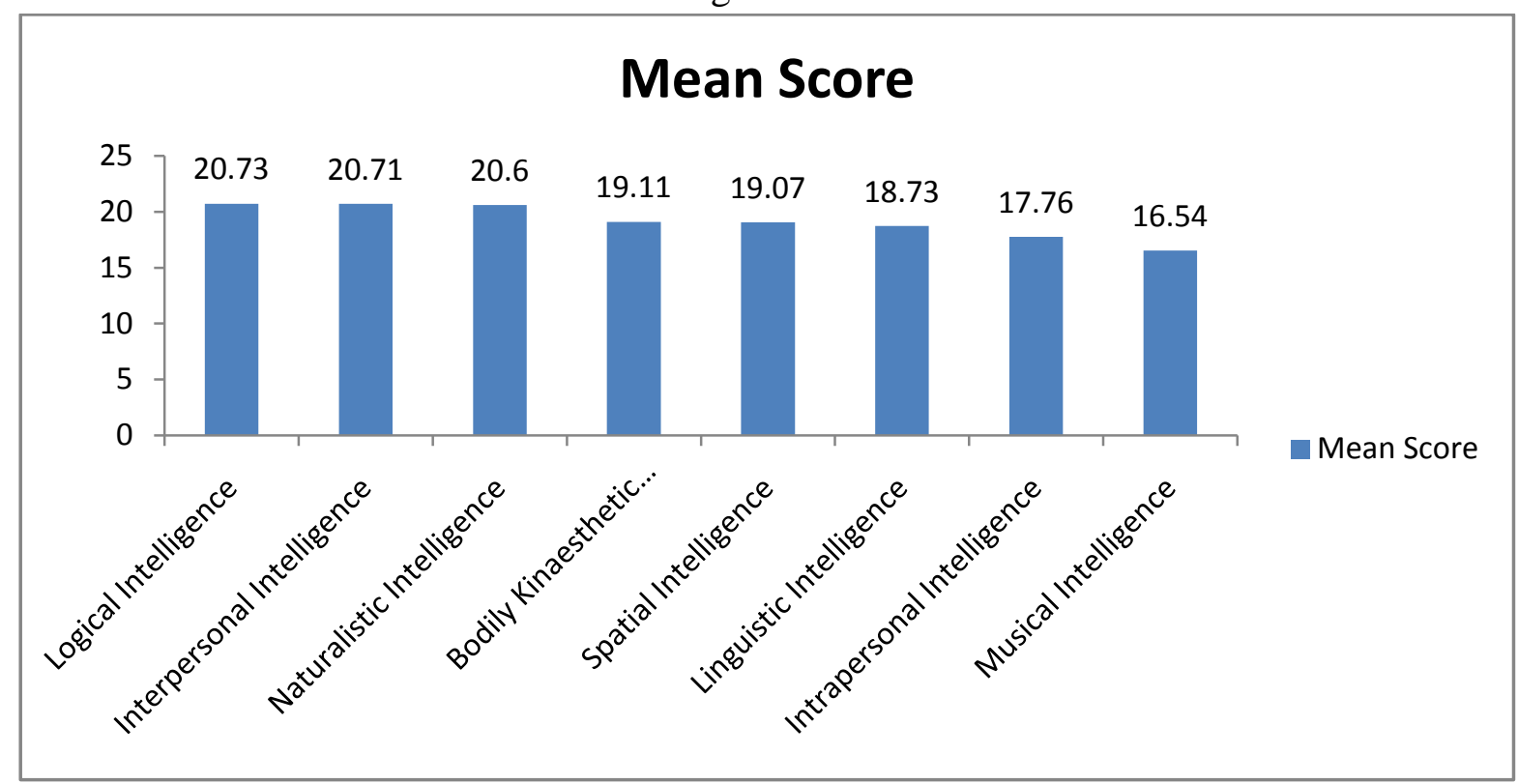

\section{Graph No.- 1}

Thus the Logical intelligence mean score and the Interpersonal intelligence mean score were higher. The proportion of Musical intelligence and the Intrapersonal intelligence were lesser.

Objective-2: To study the effect of gender on the Multiple Intelligences predispositions of the $11^{\text {th }}$ standard students.

Following null hypothesis was formulated for this objective.

\begin{tabular}{|c|c|c|c|c|c|c|c|c|}
\hline Hypothesis & Intelligence & Gender & $\mathbf{N}$ & $\mathbf{M}$ & SD & Sed & C.R. & Remarks \\
\hline \multirow{2}{*}{$\mathbf{H o}_{1.1}$} & \multirow{2}{*}{ Logical Intelligence } & Male & 205 & 21.02 & 4.18 & \multirow{2}{*}{0.41} & \multirow{2}{*}{1.56} & \multirow{2}{*}{ NS } \\
\hline & & Female & 182 & 20.38 & 3.77 & & & \\
\hline Hypothesis & Intelligence & Gender & $\mathbf{N}$ & $\mathbf{M}$ & SD & Sed & C.R. & Remarks \\
\hline \multirow{2}{*}{$\mathbf{H o}_{1.2}$} & \multirow{2}{*}{ Linguistic Intelligence } & Male & 205 & 18.67 & 3.69 & \multirow{2}{*}{0.43} & \multirow{2}{*}{0.33} & \multirow{2}{*}{ NS } \\
\hline & & Female & 182 & 18.83 & 4.70 & & & \\
\hline \multirow{2}{*}{$\mathbf{H o}_{1.3}$} & \multirow{2}{*}{ Musical Intelligence } & Male & 205 & 15.62 & 4.22 & \multirow{2}{*}{0.44} & \multirow{2}{*}{4.36} & \multirow{2}{*}{$0.01^{*}$} \\
\hline & & Female & 182 & 17.54 & 4.40 & & & \\
\hline
\end{tabular}




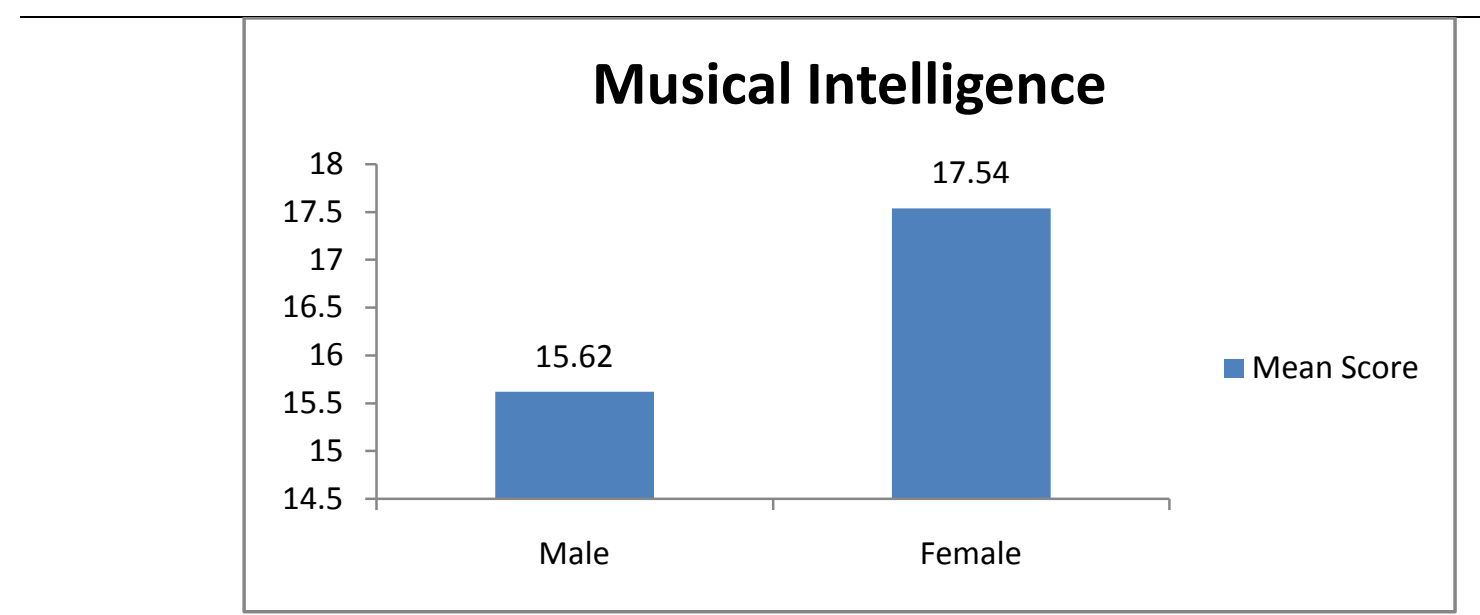

Graph No.- 2

\begin{tabular}{|c|c|c|c|c|c|c|c|c|}
\hline Hypothesis & Intelligence & Gender & $\mathbf{N}$ & $\mathbf{M}$ & SD & Sed & C.R. & Remarks \\
\hline \multirow[b]{2}{*}{$\mathbf{H o}_{1.4}$} & \multirow{2}{*}{ Spatial Intelligence } & Male & 205 & 19.12 & 3.54 & \multirow{2}{*}{0.41} & \multirow{2}{*}{0.27} & \multirow{2}{*}{ NS } \\
\hline & & Female & 182 & 19.01 & 4.37 & & & \\
\hline \multirow{2}{*}{$\mathbf{H o}_{1.5}$} & \multirow{2}{*}{$\begin{array}{l}\text { Bodily-Kinaesthetic } \\
\text { Intelligence }\end{array}$} & Male & 205 & 19.06 & 3.88 & \multirow{2}{*}{0.45} & \multirow{2}{*}{0.19} & \multirow{2}{*}{ NS } \\
\hline & & Female & 182 & 19.15 & 4.92 & & & \\
\hline \multirow{2}{*}{$\mathbf{H o}_{1.6}$} & \multirow{2}{*}{ Interpersonal Intelligence } & Male & 205 & 20.77 & 3.64 & \multirow{2}{*}{0.42} & \multirow{2}{*}{0.21} & \multirow{2}{*}{ NS } \\
\hline & & Female & 182 & 20.08 & 4.58 & & & \\
\hline \multirow{2}{*}{$\mathbf{H o}_{1.7}$} & \multirow{2}{*}{ Intrapersonal Intelligence } & Male & 205 & 17.43 & 4.08 & \multirow{2}{*}{0.44} & \multirow{2}{*}{1.55} & \multirow{2}{*}{ NS } \\
\hline & & Female & 182 & 18.12 & 4.55 & & & \\
\hline \multirow{2}{*}{$\mathbf{H o}_{1.8}$} & \multirow{2}{*}{ Naturalist Intelligence } & Male & 205 & 21.31 & 3.51 & \multirow{2}{*}{0.38} & \multirow{2}{*}{3.95} & \multirow{2}{*}{$0.01^{*}$} \\
\hline & & Female & 182 & 19.79 & 3.98 & & & \\
\hline
\end{tabular}

*- Significant difference at 0.01 level

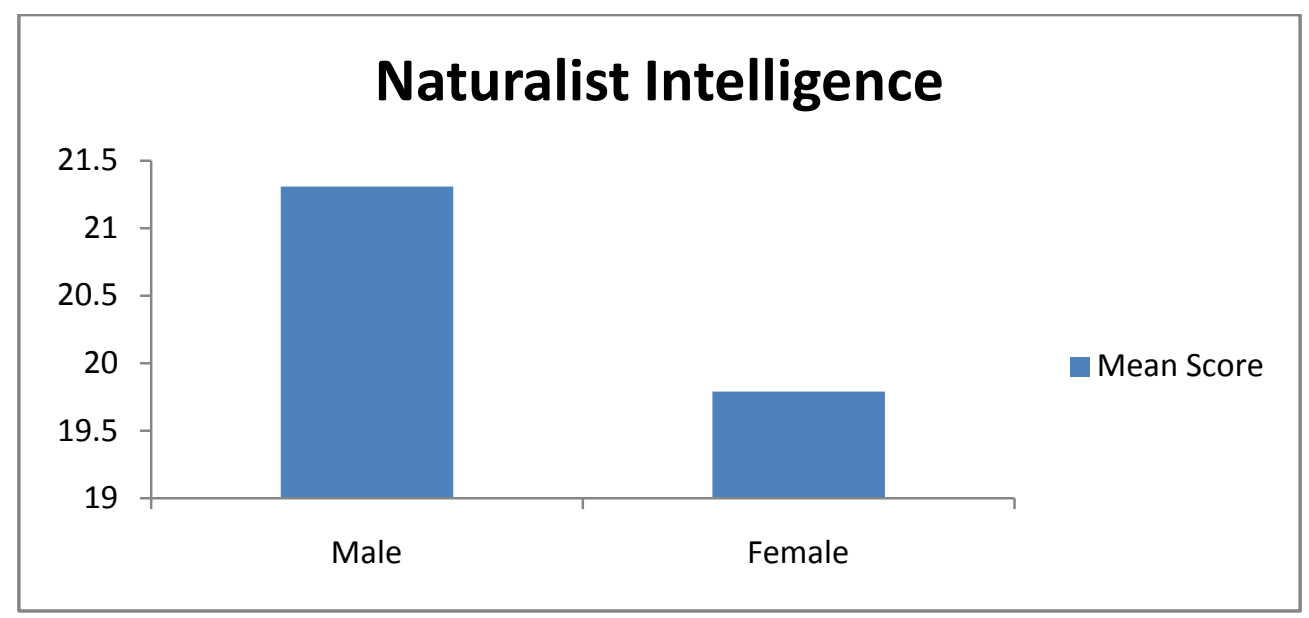

Graph No.- 3

\section{FINDINGS}

1. There was significant effect of gender on the Musical intelligence. Female students were superior to male students in Musical intelligence. 


\section{A Study of Multiple Intelligences of Students in Context to Gender}

2. There was significant effect of gender on the Naturalistic intelligence. Male students were superior to female students in Naturalistic intelligence.

3. There was no significant effect of gender on Logical Intelligence, Linguistic Intelligence, Spatial Intelligence, Bodily-Kinaesthetic Intelligence, Interpersonal Intelligence and Intrapersonal Intelligence.

\section{IMPLICATIONS}

Following were the implications based on the findings:

1. The female students should be motivated to take part in the musical programmes in the co-curricular activities of higher secondary schools.

2. There should be arrangement of training programmes related to music for the female students.

3. The male students can be suggested nature related courses during educational guidance.

\section{CONCLUSION}

The present study was conducted to know the Multiple Intelligences of the $11^{\text {th }}$ standard higher secondary school students. The findings were obtained from the data collection using survey research method. The researcher tried to create such knowledge that is useful in the world of education. This attempt will be considered fruitful if any of the findings of the study are useful in making the educational system more effective.

\section{REFERENCES}

Aysel, S. A. \& Arikan, E. K. ( 2009). 5 (2):110- 122 Journal of Theory and Practice in Buch, M.B. (Ed.) (1997). Fifth Survey of Research in Education. New Delhi: NCERT. Buch, M.B. (Ed) (2006). Sixth Survey of Research in Education. New Delhi: NCERT. Desai, H.G. (1979). Style Manual for Disserations/Theses. Rajkot :Saurastra University. Garrett H.E \& Woodworth, R.S.(1969).Statistics in Phychology and Education. Bombay : Vakils, Fecffer \& Simons Pvt. Ltd.

Gokhan BAŞ \& Omer Beyhan (2010). Effects of multiple intelligences supported project-based learning on students' achievement levels and attitudes towards English lesson International Electronic. Journal of Elementary Education Vol. 2, Issue 3, July, 2010. Retrieved on 22 ${ }^{\text {nd }}$ November 2010 from http://www.iejee. com/2_3_2010/365-385.pdf

Howard, G. (2000). Intelligence reframed. New York park avenue Basic books. Retrieved on $15^{\text {th }}$ October 2010 http://www.amazon.com/The-Unschooled-Mind-Children-Schools

Howard, G. (2006). Frames of mind. New York park avenue Basic books. Retrieved on $11^{\text {th }}$ October 2010 from http://www.amazon.com/Frames-Mind-Theory-Multiple-Intelligences Education Retrieved on 22 ${ }^{\text {nd }}$ November 2010 from http://www.eric.ed.gov /PDFS/ED506218.pdf

How to cite this article: J Joshi (2016), A Study of Multiple Intelligences of Students in Context to Gender, International Journal of Indian Psychology, Volume 3, Issue 3, No. 9, DIP: 18.01.157/20160303, ISBN: 978-1-365-13820-1 